\title{
Configurational Stability of [5]Helicenes
}

Ravat, Prince ; Hinkelmann, Rahel ; Steinebrunner, David ; Prescimone, Alessandro ; Bodoky, Ina ; Juríček, Michal

DOI: https://doi.org/10.1021/acs.orglett.7b01461

Posted at the Zurich Open Repository and Archive, University of Zurich ZORA URL: https://doi.org/10.5167/uzh-139463

Journal Article

Accepted Version

Originally published at:

Ravat, Prince; Hinkelmann, Rahel; Steinebrunner, David; Prescimone, Alessandro; Bodoky, Ina; Juríček, Michal (2017). Configurational Stability of [5]Helicenes. Organic Letters, 19(14):3707-3710.

DOI: https://doi.org/10.1021/acs.orglett.7b01461 


\title{
Configurational Stability of [5]Helicenes ${ }^{\pi}$
}

\author{
Prince Ravat, ${ }^{\dagger}$ Rahel Hinkelmann, ${ }^{\dagger}, \ddagger$ David Steinebrunner, ${ }^{\dagger,}$ Alessandro Prescimone, ${ }^{\dagger}$ Ina Bodoky, ${ }^{\dagger}$ \\ and Michal Juríček ${ }^{*,+, \|}$
}

\author{
${ }^{\dagger}$ Department of Chemistry, University of Basel, St. Johanns-Ring 19, CH-4056 Basel, Switzerland \\ *Institute of Organic Chemistry, University of Freiburg, Albertstrasse 21, 79104 Freiburg, Germany \\ ${ }^{\S}$ Institute of Applied and Physical Chemistry, University of Bremen, Leobener Strasse UFT, 28359 Bremen, Germany \\ "Department of Chemistry, University of Zurich, Winterthurerstrasse 190, CH-8057 Zurich, Switzerland
}

\begin{abstract}
A series of [5] helicenes difunctionalized in the fjord region with either fluoro, methoxy, or methyl groups was synthesized via photochemical and benzylic coupling route. Resolution of each compound into enantiomers and determination of the Gibbs activation energies of enantiomerization $\left(\Delta G^{\ddagger}(T)\right)$ revealed high configurational stability in all three cases. The $\Delta G^{\ddagger}(T)$ values of difunctionalized [5]helicenes were compared with those of their monofunctionalized analogs and the parent [5] helicene. Within this series, an exponential correlation between the torsional twist and $\Delta G^{\ddagger}(T)$ was found. The dimethyl derivative exhibits one of the highest configurational stabilities among $[n]$ helicenes reported to date, comparable to that of [9] helicene.
\end{abstract}

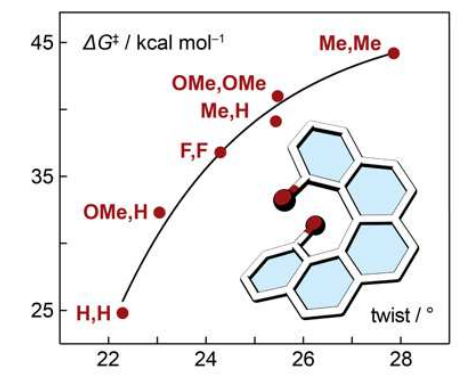

It was not long ago that we commemorated ${ }^{1}$ the $100^{\text {th }}$ anniversary of $[n]$ helicenes, $\pi$-delocalized systems comprised of $n$ ortho-fused benzenoid rings. When $n>3,[n]$ helicenes adopt helically twisted geometries that are axially chiral ${ }^{2}$ and possess electronic properties that are distinctly different from those ${ }^{3}$ of the linear meta-fused acenes. To date, $[n]$ helicenes and their derivatives have found applications as chiral ligands in enantioselective catalysis, ${ }^{4}$ sensors, ${ }^{5}$ and chiroptical switches, ${ }^{6}$ among others. Recently, $[n]$ helicene-based nanographenes ${ }^{7}$ and openshell molecules ${ }^{8}$ have emerged, sought for their potential applications in materials chemistry and organic electronics.

An important stereodynamic feature of $[n]$ helicenes, when chirality comes into play, is configurational stability. It relates to the Gibbs activation energy of enantiomerization $\left(\Delta G^{\ddagger}(T)\right)$, which increases with increasing $n$ (or steric hindrance) and dictates whether a compound can or cannot be separated into enantiomers under defined conditions (herein, room temperature). We would like to note that in literature, there is a significant degree of misconception regarding the correct way ${ }^{9}$ of calculating $\Delta G^{\ddagger}(T)$. To maximize the accuracy of our analysis described herein, we therefore re-calculated, when necessary and possible, the originally reported $\Delta G^{\ddagger}(T)$ values (Section S6, Supporting Information) and use those in our main text discussion, Table 1, and Figure 3.

The first helical member, [4] helicene, ${ }^{10}$ is configurationally unstable, which means that it cannot be isolated in an enantioenriched form at room temperature, unless substituents are introduced $^{11}$ at positions 1 and 12 to increase its configurational stability. The second member, [5]helicene, ${ }^{12}$ can be resolved into enantiomers but the enantioenriched samples fully racemize over several days under ambient conditions. [6]Helicene ${ }^{13}$ is the first member that is configurationally stable and the
$\Delta G^{\ddagger}(T)$ values of higher $[n]$ helicenes $(n>6)$ follow ${ }^{14}$ an exponential trend (Figure $3 \mathrm{~b}$ ), with an upper limit of $\Delta G^{\ddagger}(503 \mathrm{~K}) \sim$ $44 \mathrm{kcal} \mathrm{mol}^{-1}$ (the largest reported $\Delta G^{\ddagger}(T)$ for any $[n]$ helicene is that of [9] helicene, $\left.{ }^{14 \mathrm{c}} \Delta G^{\ddagger}(503 \mathrm{~K})=44.1 \mathrm{kcal} \mathrm{mol}^{-1}\right)$. These results indicate that $[n]$ helicenes are "much more "flexible" than it is generally believed', as pointed out ${ }^{1 \mathrm{e}, 14 \mathrm{c}}$ by Martin.

Configurational stability of $[n]$ helicenes can be improved by installment $^{14 \mathrm{~b}, 15}$ of substituents at various positions, where additional steric hindrance can arise. This strategy is particularly useful for increasing ${ }^{15 a}$ configurational stability of $[n]$ helicenes with $n<6$. Among these, [5]helicene (1, Figure 1) is the best candidate, as it displays partial configurational stability (vide supra). As demonstrated ${ }^{16}$ on the series of monofunctionalized [5]helicenes, only substituents installed at position 1 (2, Figure 1) markedly increase $\Delta G^{\ddagger}(T)$. Depending on the size of the substituent, Gibbs activation energy as high ${ }^{16 \mathrm{~b}}$ as $\Delta G^{\star}(473 \mathrm{~K})=$ $39.1 \mathrm{kcal} \mathrm{mol}^{-1}(\mathbf{2 c}, \mathrm{R}=\mathrm{Me})$ - and thus stability against racemization at room temperature - can be achieved.

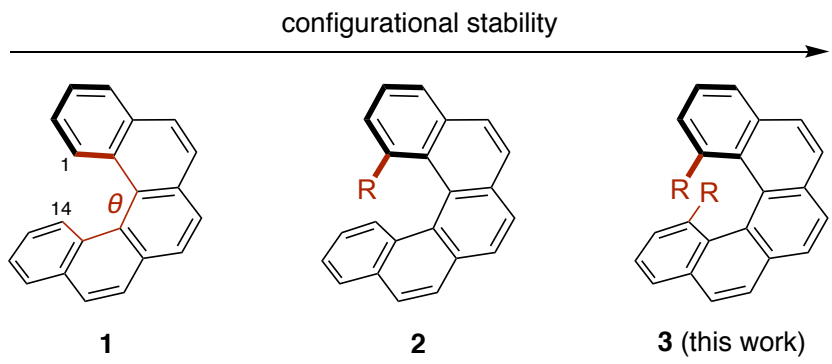

Figure 1. Structural formulae of non-, mono-, and difunctionalized [5]helicenes. $\mathrm{R}=\mathrm{F}(\mathbf{2} \mathbf{a}, \mathbf{3 a}), \mathrm{OMe}(\mathbf{2} \mathbf{b}, \mathbf{3 b}), \mathrm{Me}(\mathbf{2 c}, \mathbf{3 c})$. 
Although relatively many 1,14 -difunctionalized [5] helicenes have been ${ }^{17}$ reported, there are only a few cases when the enantiomers were resolved ${ }^{18}$ and, to the best of our knowledge, there is no case when activation parameters of enantiomerization have been ${ }^{19}$ determined. To deepen our understanding, we investigated configurational stability of a series of [5] helicenes 3 (Figure 1), bearing either two fluoro (3a), two methoxy (3b), or two methyl (3c) substituents at positions 1 and 14 in the fjord region. All three compounds were resolved into enantiomers and their $\Delta G^{\ddagger}(T)$ values were determined for the first time to systematically analyze the steric effect of the substituents on $\Delta G^{\ddagger}(T)$ and correlate these results with those obtained for 1monofunctionalized [5] helicenes ${ }^{16 \mathrm{~b}}$ and parent [5]helicene. ${ }^{12,20}$ Our findings reveal new insights regarding configurational stability of $[n]$ helicenes and indicate that difunctionalization in the fjord region of [5]helicenes can push the configurational stability to the limit, reaching the bar $\operatorname{set}^{14 c}$ by [9]helicene. In addition, two substituents installed in the fjord region allow the use of a photocyclodehydrogenation ${ }^{17 \mathrm{c}, 21}$ protocol (Scheme 1) for the synthesis of [5]helicenes, the most powerful method ${ }^{22}$ for the preparation of $[n]$ helicenes to date. The use of this method is cumbersome in the case of 1,14-unsubstituted [5] helicenes ${ }^{23}$ because of the subsequent photocyclodehydrogenation step leading to planar byproduct and in the case of 1-fluoro-[5]helicenes ${ }^{24}$ such as $\mathbf{2 a}$ on account of substituent migration/loss. Because the practicability of the photochemical method is limited by reaction scale and previous methods for the preparation of 1,14-difunctionalized [5] helicenes via metal-catalyzed cycloisomerization $^{16}$ or tandem radical cyclization ${ }^{17 a}$ are not advantageous, we explored an alternative route that employs benzylic coupling $^{25}$ as the key step (Schemes 2 and 3).

\section{Scheme 1. The Photochemical Route to 3a-3c}

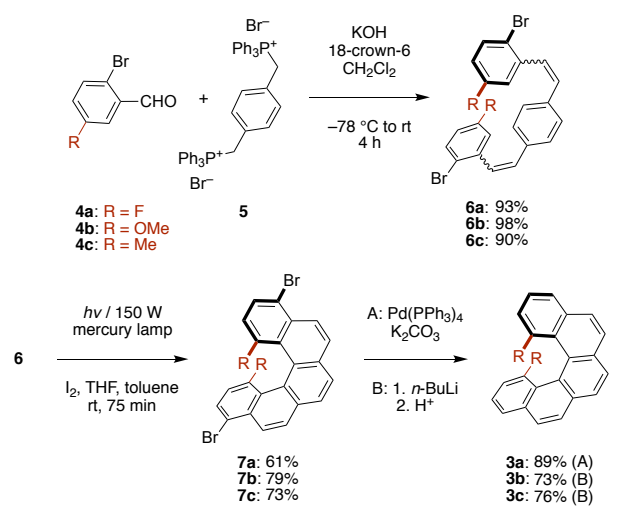

The photochemical route to the target compounds $\mathbf{3 a}-\mathbf{3} \mathbf{c}$ employed photocyclodehydrogenation of stilbene-type precursors 6a-6c as the key step (Scheme 1). The terminal benzene rings of $\mathbf{6 a}-\mathbf{6 c}$ were each equipped with the respective R group and a bromo substituent, which blocked one of the two possible positions for photocyclodehydrogenation to control the selectivity of this step. The structures of the corresponding products $7 \mathbf{a}-7 \mathbf{c}$ were confirmed by 2D NMR spectroscopic techniques and by single-crystal X-ray diffraction (XRD) analysis (Supporting Information). We found that $\mathbf{7 a}$ and $\mathbf{7 b}$ crystallized in achiral space groups, while 7c crystallized in a chiral Sohncke space group, which is rare ${ }^{17 a}$ for [5] helicenes. In the last step, debromination of $7 \mathbf{a}-\mathbf{7} \mathbf{c}$ afforded the target compounds $\mathbf{3 a}-\mathbf{3 c}$. This route affords the target compounds in three steps from $\mathbf{4}$ and $\mathbf{5}$ and is only limited by high-dilution conditions ${ }^{17 \mathrm{c}}$ of the photochemical step $\left(\sim 10^{-3} \mathrm{M}\right)$.
For compounds $\mathbf{3 a}$ and $\mathbf{3 b}$, we therefore tested the practicability of a non-photochemical approach (Schemes 2 and 3), which employs the benzylic coupling ${ }^{25}$ as the key step for the construction of the [5] helicene core. This approach requires the intermediacy of $\mathbf{1 0}$ and 13, 2,2'-dimethyl-1,1'-binaphthalenes with additional substituents at positions 8 and 8 ', which were hitherto unknown. The difluoro derivative $\mathbf{1 0}$ was synthesized (Scheme 2) in five steps in an overall $45 \%$ yield from $\mathbf{8}$. Tetrabromination of $\mathbf{1 0}$ with an excess of $N$-bromosuccinimide (NBS) followed by the benzylic coupling mediated by $t$-BuOK afforded $7 \mathbf{a}^{\prime}$ in $64 \%$ yield over the two steps. Debromination of $7 \mathbf{a}^{\prime}$ ( or 7a) with $n$-BuLi/MeOH failed, giving a mixture of unknown products, while debromination of $7 \mathbf{a}^{\prime}$ with $\mathrm{Pd}$ catalyst under basic conditions afforded $\mathbf{3 a}$ in $89 \%$ yield.

Scheme 2. The Benzylic Coupling Route to 3a

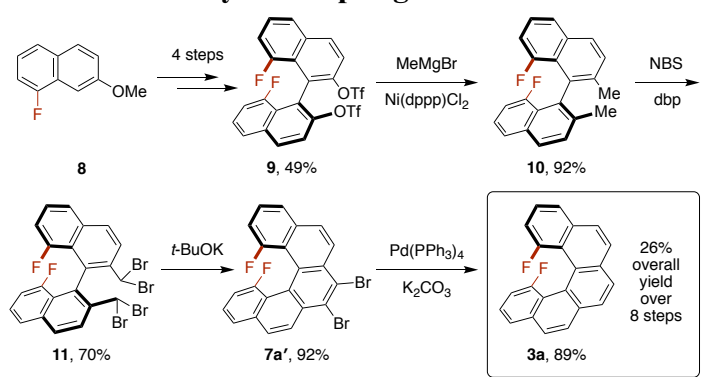

The dimethoxy derivative $\mathbf{1 3}$ was synthesized (Scheme 3 ) in four steps in an overall $60 \%$ yield from 12. When reacted with NBS in the presence of dibenzoyl peroxide (dbp), 13 first undergoes electrophilic bromination at positions 5 and 5 ' to afford the dibromo intermediate $\mathbf{1 4}$ and then the desired benzylic bromination to afford the tetrabromo intermediate 15. Best yields were achieved when this reaction was not performed in one but in two steps, affording 15 in $64 \%$ overall yield from $\mathbf{1 3}$. The benzylic coupling of $\mathbf{1 5}$ gave $\mathbf{7 b}$ in $81 \%$ yield, which upon treatment with $n-\mathrm{BuLi} / \mathrm{MeOH}$ afforded the desired product $\mathbf{3 b}$ in $73 \%$ yield. This route cannot be applied to $\mathbf{3 c}$, because benzylic bromination of $2,2^{\prime}, 8,8^{\prime}$-tetramethyl-1,1'-binaphthalene would not proceed selectively at positions 2 and $2^{\prime}$. Compound $\mathbf{3 c}$ could, however, be prepared from $\mathbf{3 b}$, by transforming the methoxy groups into the methyl groups.

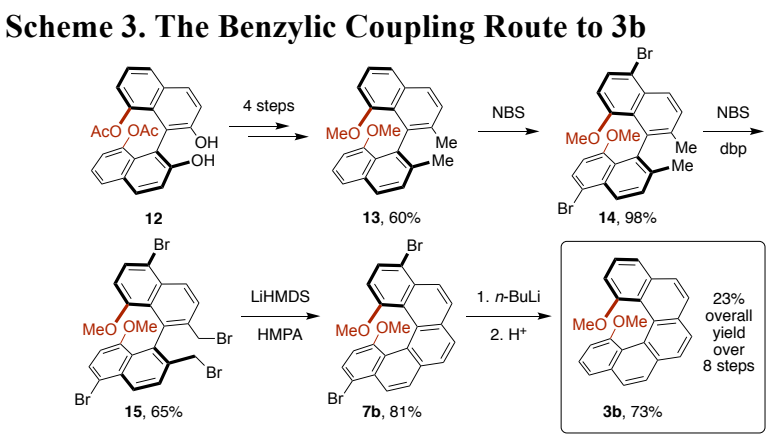

Overall, the photochemical route provided $\mathbf{3 a}$ and $\mathbf{3 b}$ over three steps in $51 \%$ and $57 \%$ overall yield, respectively, while the benzylic coupling route afforded $\mathbf{3 a}$ and $\mathbf{3 b}$ over eight steps in $26 \%$ and $23 \%$ overall yield, respectively. Moreover, the starting materials $\mathbf{8}$ and $\mathbf{1 2}$ for the latter route need to be pre-synthesized. In terms of efficiencies, the photochemical route therefore wins over the other methods despite its scale limitation, which can be overcome ${ }^{26}$ by continuous flow techniques. 

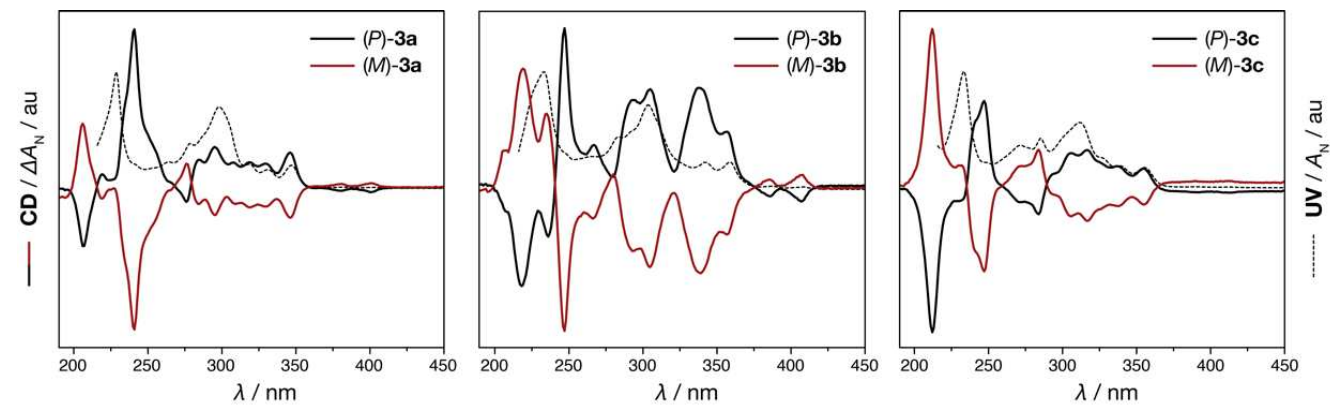

Figure 2. UV-vis and ECD spectra of 3a-3c, as eluted from HPLC in $n$-hexane/i-PrOH (2-5\%) at $20{ }^{\circ} \mathrm{C}$. $\mathrm{Spectra}$ in $\mathrm{CHCl}_{3}($ absorptions above $240 \mathrm{~nm}$ ) at known concentration are shown in the Supporting Information.

The configurational stability of $\mathbf{3 a} \mathbf{a}-\mathbf{3 c}$ was assessed by determining their $\Delta G^{\ddagger}(T)$ values. These were obtained by resolution of $\mathbf{3 a}-\mathbf{3} \mathbf{c}$ into enantiomers by use of HPLC on a chiral stationary phase and then by following the decay of the enantiomeric excess (ee) at a particular temperature over time (Supporting Information). The enantioenriched samples displayed mirror-image electronic circular dichroism (ECD) spectra (Figure 2) and the absolute configuration of each enantiomer was determined ${ }^{27}$ (Supporting Information) with the aid of TD-DFT calculations at the B3LYP/6-31G(d,p) level. The electronic nature of the two substituents in the fjord region clearly influences the electronic structure of each compound, as reflected both by the UV-vis and ECD spectra (Figure 2). The solution of each enantioenriched sample was then heated at a suitable elevated temperature $(T)$ and the decay of the ee was followed over time $(t)$ by HPLC on a chiral stationary phase. The $\ln \left(e e_{t} / e e_{0}\right)$ against $t$ plot of these data allowed determination of the rate constant of enantiomerization $\left(k_{\mathrm{e}}\right)$ and thus calculation of the $\Delta G^{\ddagger}(T)$ values (Table 1), which indicate that $\mathbf{3 a}-\mathbf{3 c}$ are all stable against racemization at room temperature.

Next, we were curious to see if there is any correlation between the size of the substituent (quantified by the $A$ values ${ }^{28}$ ) and $\Delta G^{\ddagger}(T)$ of the fjord-substituted [5] helicenes 2 and 3. From the $A$ and $\Delta G^{\ddagger}(T)$ values (Table 1 ), it is evident that as the steric bulk of the substituent increases (in the order $\mathrm{F}<\mathrm{OMe}<\mathrm{Me}$ ), $\Delta G^{\ddagger}(T)$ increases as well, both throughout series $2^{16 \mathrm{~b}}$ (data for 2a are not available) and $\mathbf{3}$. The highest value $\left(\Delta G^{\ddagger}(503 \mathrm{~K})=\right.$ $44.2 \mathrm{kcal} \mathrm{mol}^{-1}$ ) was obtained for dimethyl derivative $3 \mathrm{c}$. To correlate all compounds from series $\mathbf{2}$ and $\mathbf{3}$ as well as parent $\mathbf{1}$ together, the combined steric effect of $\mathrm{H} / \mathrm{H}, \mathrm{R} / \mathrm{H}$, and R/R' substituents had to be quantified. We found that both (1) the distance $(d)$ between the carbon atoms at positions 1 and 14 and (2) torsional twist $(\theta)$ of the [5]helicene core can be used as the measures of the 'total' steric bulk. An illustrative plot of the $\Delta G^{\ddagger}(T)$ values against the $\theta$ values is shown in Figure 3a. Despite the fact that the $\Delta G^{\ddagger}(T)$ values correspond to different temperatures within the range $423-503 \mathrm{~K}$, a clear exponential trend with an upper $\Delta G^{\ddagger}(T)$ limit of $\sim 46-47 \mathrm{kcal} \mathrm{mol}^{-1}$, almost reached by $3 \mathbf{c}$, is visible. One can also see that one methyl substituent in $2 \mathrm{c}$ causes a larger total steric bulk, and consequently larger $d, \theta$, and $\Delta G^{\ddagger}(T)$, than two fluoro substituents in 3a but it does not exceed the effect of two methoxy substituents in $\mathbf{3 b}$. Using this plot, the $\Delta G^{\ddagger}(T)$ value for $2 \mathbf{a}\left(\sim 32 \mathrm{kcal} \mathrm{mol}^{-1}\right.$ at $423-$ $503 \mathrm{~K}$ ), which is not available by experiment, can be extrapolated. It is noteworthy to mention that $\mathbf{3 c}$ displays an extreme torsional twist $\left(28^{\circ}\right)$, surpassing all reported [5]helicenes.

Parent $[n]$ helicenes follow a similar trend: as $n$ increases, $\Delta G^{\ddagger}(T)$ increases $^{14}$ exponentially with an upper limit of $\sim 44 \mathrm{kcal}$ $\mathrm{mol}^{-1}$ at $503 \mathrm{~K}$ (Figure $3 \mathrm{~b}$, black). Using our and previously reported $^{14 \mathrm{c}, 15,16 \mathrm{~b}, 29}$ data, we analyzed if this is the case also for mono- (red/black) and dimethyl (red) $[n]$ helicenes (Figure 3b). In both cases, an exponential dependence of $\Delta G^{\ddagger}$ on $n$ is observed, with an upper limit of $\sim 44 \mathrm{kcal} \mathrm{mol}^{-1}$. The difference is that the bar (dashed horizontal lines), reached by [9] helicene in the unsubstituted series, is reached already by [6]- and [5] helicene in the case of mono- and dimethylated series, respectively. These results indicate that substitution in the fjord region of $[n]$ helicenes is a more efficient way to increase the configurational stability than elongation of the helical core.
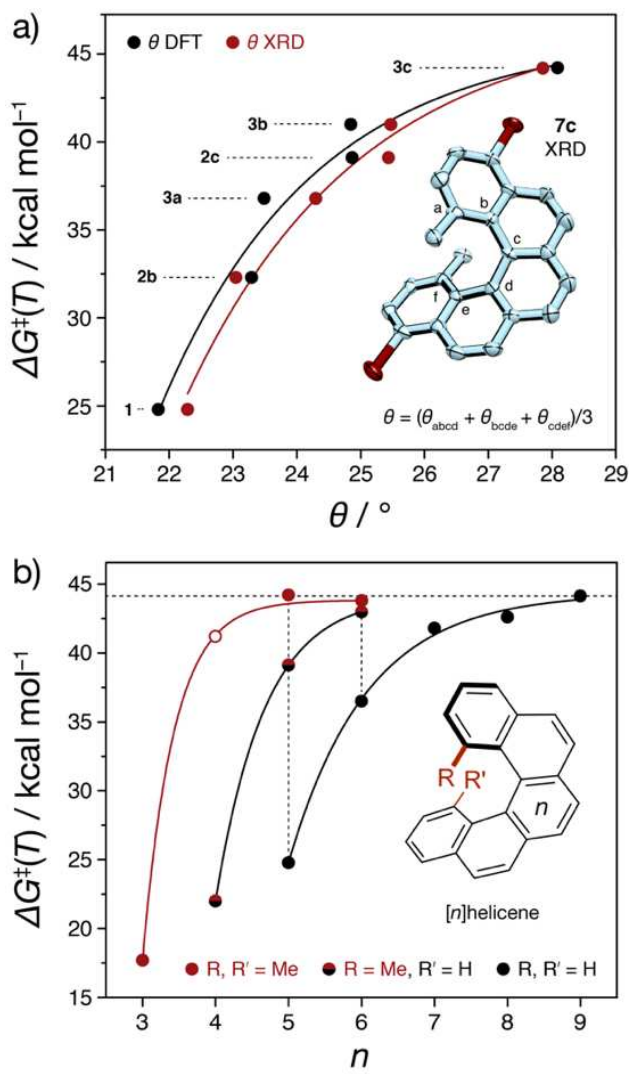

Figure 3. (a) A plot of $\Delta G^{\ddagger}(T)$ values against torsional twist $(\theta)$ for 1, 2, and 3. In the inset: the solid-state structure of 7c. (b) A plot of $\Delta G^{\ddagger}(T)$ values against the number of fused rings $(n)$ for parent (black), mono- (red/black) and dimethyl (red) fjord-substituted $[n]$ helicenes. The white-filled red circle is extrapolated. 
Table 1. An Overview of Structural and Stereodynamic Parameters for Selected [5]Helicenes ${ }^{a}$

\begin{tabular}{|c|c|c|c|c|c|c|c|c|c|}
\hline compd & $\mathrm{R}$ & $\mathrm{R}^{\prime}$ & $A(\mathrm{R})^{b}$ & $d_{\mathrm{XRD}}(\AA)^{c}$ & $d_{\mathrm{DFT}}(\AA)^{c, d}$ & $\theta_{\mathrm{XRD}}\left({ }^{\circ}\right)^{e}$ & $\theta_{\mathrm{DFT}}\left({ }^{\circ}\right)^{d, e}$ & $\Delta G^{\ddagger}\left(\mathrm{kcal} \mathrm{mol}^{-1}\right)^{f}$ & temp $(\mathrm{K})^{f}$ \\
\hline 1 & $\mathrm{H}$ & $\mathrm{H}$ & 0 & $2.934^{g, h}$ & 2.956 & $22.29^{g, h}$ & 21.83 & $24.8^{i}$ & 463 \\
\hline $2 \mathbf{a}$ & $\mathrm{F}$ & $\mathrm{H}$ & 0.15 & - & 3.041 & - & 22.87 & - & - \\
\hline $2 b$ & $\mathrm{OMe}$ & $\mathrm{H}$ & 0.60 & $2.986^{j}$ & 3.054 & $23.05^{j}$ & 23.29 & $32.3^{j, k}$ & 423 \\
\hline $2 \mathrm{c}$ & $\mathrm{Me}$ & $\mathrm{H}$ & 1.7 & $3.074^{j}$ & 3.123 & $25.44^{j}$ & 24.87 & $38.1^{j, k}$ & 473 \\
\hline $3 \mathbf{a}$ & $\mathrm{F}$ & $\mathrm{F}$ & 0.15 & $3.151^{h, l}$ & 3.162 & $24.13^{h, l}$ & 23.49 & 36.8 & 466 \\
\hline $\mathbf{3 b}$ & $\mathrm{OMe}$ & OMe & 0.60 & $3.141^{l}$ & 3.203 & $25.48^{l}$ & 24.85 & 41.0 & 483 \\
\hline $3 c$ & $\mathrm{Me}$ & $\mathrm{Me}$ & 1.7 & $3.257^{l}$ & 3.324 & $27.86^{l}$ & 28.09 & 44.2 & 503 \\
\hline
\end{tabular}

${ }^{a}$ General structure is shown in Figure $3 b .{ }^{b}$ The $A$ value (see ref 28) of substituent R. ${ }^{c}$ Distance between the carbon atoms at positions 1 and 14 (Figure 1). ${ }^{d}$ DFT/B3LYP/6-31G(d,p), this work. ${ }^{e}$ An average value of torsional angles of all phenanthrene subunits of [5]helicene. ${ }^{f}$ Experimental Gibbs activation energies of enantiomerization $\left(\Delta G^{\ddagger}\right)$ at temperature $T .{ }^{g}$ See ref $20 .{ }^{h}$ Two molecules in the asymmetric unit, the average value of the two structures was taken. ${ }^{i}$ See ref $12 .{ }^{j}$ See ref 16b. ${ }^{k}$ Re-calculated (see Section S6 in the Supporting Information). ${ }^{l}$ Obtained from the solidstate structure of the corresponding dibromo derivative 7 (see Scheme 1).

To conclude, our findings support Martin's argument ${ }^{14 \mathrm{c}}$ that the thermal enantiomerization of $[n]$ helicenes proceeds through the conformational pathway, as fjord-substituents severely impact their configurational stability. In particular, two methyl substituents were found to induce an extreme torsional twist $\left(28^{\circ}\right)$ in $3 \mathbf{c}$ and push its $\Delta G^{\ddagger}(T)=44.2 \mathrm{kcal} \mathrm{mol}^{-1}$ to the limit $\left(\sim 44 \mathrm{kcal} \mathrm{mol}^{-1}\right)$ set by [9]helicene, which has not yet been exceeded by an $[n]$ helicene. The question remains whether this energy bar can be exceeded through the steric effect of even more bulky ${ }^{19 a}$ fjord-substituents, and whether such molecules are within the synthetic reach. [5]Helicenes with high configurational stability such as $\mathbf{3 c}$ can find use in the enantioselective catalysis at elevated temperatures and in the design of chiral open-shell nanographenes.

\section{ASSOCIATED CONTENT}

\section{Supporting Information}

The Supporting Information is available free of charge on the ACS Publications website.

Experimental procedures, characterization and kinetic data (PDF) Crystallographic data for $\mathbf{7 a}, \mathbf{7 b}$, and $\mathbf{7 c}$ (CIF)

\section{AUTHOR INFORMATION}

\section{Corresponding Author}

*michal.juricek@chem.uzh.ch

\section{Notes}

The authors declare no competing financial interest.

\section{ACKNOWLEDGMENT}

We sincerely thank Prof. Dr. Marcel Mayor for a generous support of our research at the University of Basel, PD Dr. Daniel Häussinger (University of Basel) for NMR measurements, and Prof. Dr. Oliver Trapp (Ludwig-Maximilian University of Munich) for useful discussions on kinetics. This project has received funding from the European Research Council (ERC) under the European Union's Horizon 2020 research and innovation programme (grant agreement No 716139). We gratefully acknowledge financial support from the Swiss National Science Foundation (SNSF, M.J./PZ00P2_148043 and PP00P2_170534) and the Novartis University of Basel Excellence Scholarship (P.R. and M.J.).

\section{REFERENCES}

"In memory of Richard Henri Martin (1914-1995)
1. (a) Gingras, M. Chem. Soc. Rev. 2013, 42, 968-1006. (b) Gingras, M.; Félix, G.; Peresutti, R. Chem. Soc. Rev. 2013, 42, 1007-1050. (c) Gingras, M. Chem. Soc. Rev. 2013, 42, 1051-1095. (d) Shen, Y.; Chen, C.-F. Chem. Rev. 2012, 112, 1463-1535. (e) Martin, R. H. Angew. Chem. Int. Ed. 1974, 13, 649-660.

2. Rickhaus, M.; Mayor, M.; Juríček, M. Chem. Soc. Rev. 2016, 45, $1542-1556$.

3. Sapir, M.; Vander Donckt, E. Chem. Phys. Lett. 1975, 36, 108 110 .

4. (a) Aillard, P.; Voituriez, A.; Marinetti, A. Dalton Trans. 2014, 43, 15263-15278. (b) Narcis, M. J.; Takenaka, N. Eur. J. Org. Chem. 2014, 21-34. (c) Peng, Z.; Takenaka, N. Chem. Rec. 2013, 13, $28-42$.

5. Chen, C.-F.; Shen, Y. Recognition, Sensors, and Responsive Switches. In Helicene Chemistry: From Synthesis to Applications; Springer: Heidelberg, 2017; pp 201-220.

6. Isla, H.; Crassous, J. C. R. Chimie 2016, 19, 39-49.

7. (a) Hu, Y.; Wang, X.-Y.; Peng, P.-X.; Wang, X.-C.; Cao, X.-Y.; Feng, X.; Müllen, K.; Narita, A. Angew. Chem. Int. Ed. 2017, 56, 33743378. (b) Fujikawa, T.; Preda, D. V.; Segawa, Y.; Itami, K.; Scott, L. T. Org. Lett. 2016, 18, 3992-3995. (c) Yano, Y.; Ito, H.; Segawa, Y.; Itami, K. Synlett 2016, 27, 2081-2084. (d) Fujikawa, T.; Segawa, Y.; Itami, K. J. Am. Chem. Soc. 2016, 138, 3587-3595.

8. (a) Ravat, P.; Ribar, P.; Rickhaus, M.; Häussinger, D.; Neuburger, M.; Juríček, M. J. Org. Chem. 2016, 81, 12303-12317. (b) Ravat, P.; Šolomek, T.; Ribar, P.; Juríček, M. Synlett 2016, 27, 1613-1617. (c) Ravat, P.; Šolomek, T.; Rickhaus, M.; Häussinger, D.; Neuburger, M.; Baumgarten, M.; Juríček, M. Angew. Chem. Int. Ed. 2016, 55, 11831186. (d) Liu, J.; Ravat, P.; Wagner, M.; Baumgarten, M.; Feng, X.; Müllen, K. Angew. Chem. Int. Ed. 2015, 54, 12442-12446.

9. Schoetz, G.; Trapp, O.; Schurig, V. Electrophoresis 2001, 22, 3185-3190.

10. Newman, M. S.; Wolf, M. J. Am. Chem. Soc. 1952, 74, 32253228.

11. (a) Kemp, C. M.; Mason, S. F. Chem. Commun. 1965, 559-560. (b) Newman, M. S.; Mentzer, R. G.; Slomp, G. J. Am. Chem. Soc. 1963, $85,4018-4020$.

12. Goedicke, C.; Stegemeyer, H. Tetrahedron Lett. 1970, 11, 937940 .

13. Martin, R. H.; Marchant, M. J. Tetrahedron Lett. 1972, 13, 3707-3708.

14. (a) Grimme, S.; Peyerimhoff, S. D. Chem. Phys. 1996, 204, 411417. (b) Janke, R. H.; Haufe, G.; Würthwein, E.-U.; Borkent, J. H. J. Am. Chem. Soc. 1996, 118, 6031-6035. (c) Martin, R. H.; Marchant, M. J. Tetrahedron 1974, 30, 347-349.

15. (a) Scherübl, H.; Fritzsche, U.; Mannschreck, A., Chem. Ber. 1984, 117, 336-343. (b) Borkent, J. H.; Laarhoven, W. H. Tetrahedron 1978, 34, 2565-2567.

16. (a) Usui, K.; Yamamoto, K.; Shimizu, T.; Okazumi, M.; Mei, B.; Demizu, Y.; Kurihara, M.; Suemune, H. J. Org. Chem. 2015, 80, 65026508. (b) Yamamoto, K.; Okazumi, M.; Suemune, H.; Usui, K. Org. Lett. 2013, 15, 1806-1809. 
17. (a) Harrowven, D. C.; Guy, I. L.; Nanson, L. Angew. Chem. Int Ed. 2006, 45, 2242-2245. (b) Stammel, C.; Fröhlich, R.; Wolff, C.; Wenck, H.; de Meijere, A.; Mattay, J. Eur. J. Org. Chem. 1999, 1709 1718. (c) Liu, L.; Yang, B.; Katz, T. J.; Poindexter, M. K. J. Org. Chem. 1991, 56, 3769-3775. (d) Laarhoven, W. H.; Boumans, P. G. F. Recl. Trav. Chim. Pays-Bas 1975, 94, 114-118.

18. (a) Shen, Y.; Lu, H.-Y.; Chen, C.-F. Angew. Chem. Int. Ed. 2014, 53, 4648-4651. (b) Tsuji, G.; Kawakami, K.; Sasaki, S. Bioorg. Med. Chem. 2013, 21, 6063-6068. (c) Yamamoto, K.; Ikeda, T.; Kitsuki, T.; Okamoto, Y.; Chikamatsu, H.; Nakazaki, M. J. Chem. Soc., Perkin Trans. 1 1990, 271-276.

19. (a) One example of fjord-difunctionalized benzo[5]helicene, where no racemization could be observed within $10 \mathrm{~h}$ at $473 \mathrm{~K}$, has recently been reported: Lin, W.-B.; Li, M.; Fang, L.; Shen, Y.; Chen, C.-F. Chem. Asian J. 2017, 12, 86-94. (b) An example of fjorddifunctionalized tetrahydro[5]helicene, where $\Delta G^{\ddagger}(T)$ was determined: Li, M.; Lu, H.-Y.; Zhang, C.; Shi, L.; Tang, Z.; Chen, C.-F. Chem. Commun. 2016, 52, 9921-9924.

20. Kuroda, R. J. Chem. Soc., Perkin Trans. 2 1982, 789-794.

21. (a) Flammang-Barbieux, M.; Nasielski, J.; Martin, R. H. Tetrahedron Lett. 1967, 8, 743-744. (b) Scholz, M.; Mühlstädt, M.; Dietz, F. Tetrahedron Lett. 1967, 8, 665-668.
22. Mori, K.; Murase, T.; Fujita, M. Angew. Chem. Int. Ed. 2015, $54,6847-6851$.

23. Liu, L.; Katz, T. J. Tetrahedron Lett. 1991, 32, 6831-6834.

24. Mallory, F. B.; Mallory, C. W. J. Org. Chem. 1983, 48, 526532.

25. (a) Goretta, S.; Tasciotti, C.; Mathieu, S.; Smet, M.; Maes, W.; Chabre, Y. M.; Dehaen, W.; Giasson, R.; Raimundo, J.-M.; Henry, C. R.; Barth, C.; Gingras, M. Org. Lett. 2009, 11, 3846-3849. (b) Dubois, F.; Gingras, M. Tetrahedron Lett. 1998, 39, 5039-5040.

26. Lefebvre, Q.; Jentsch, M.; Rueping, M. Beilstein J. Org. Chem. 2013, 9, 1883-1890.

27. (a) Nakai, Y.; Mori, T.; Inoue, Y. J. Phys. Chem. A 2012, 116, 7372-7385. (b) Furche, F.; Ahlrichs, R.; Wachsmann, C.; Weber, E.; Sobanski, A.; Vögtle, F.; Grimme, S. J. Am. Chem. Soc. 2000, 122, $1717-1724$

28. Hirsch, J. A. Table of Conformational Energies-1967. In Topics in Stereochemistry, Vol. 1; Allinger, N. L.; Eliel, E. L., Eds.; Wiley: New York, 1967; p 199.

29. Armstrong, R. N.; Ammon, H. L.; Darnow, J. N. J. Am. Chem. Soc. 1987, 109, 2077-2082. 